\title{
Offshoring, Transition, and Training: Evidence from Danish Matched Worker-Firm Data
}

\author{
David Hummels, Purdue University and NBER \\ Jakob R. Munch, University of Copenhagen \\ Lars Skipper, Aarhus University \\ Chong Xiang, Purdue University and NBER \\ November 2011
}

\section{Introduction}

Rising globalization creates both opportunities and challenges for workers. Wages depend not only on ability and effort but also on the returns to specific tasks, and rising globalization can lead to sharp changes in those task returns. Workers engaged in expanding export firms may enjoy wage gains while workers engaged in tasks that are offshored may suffer wage losses and job displacement. Hummels, Jørgensen, Munch and Xiang (2011) (HJMX 2011 henceforth) use Danish matched worker-firm-trade data to examine how workers' wages are affected by exogenous shocks to their employers' offshoring and exporting decisions. They find that for workers who remain employed, offshoring raises skilled labor wages and lowers unskilled labor wages, while exporting raises wages of all workers. The most profound effects on wages occur for the workers displaced from offshoring firms, who experience wage losses of 15\% (skilled workers) or 21\% (unskilled workers). These losses are considerably larger and more persistent than for the workers displaced for other reasons.

Most OECD countries subsidize worker training programs directly or indirectly. It is of significant policy interest whether these programs succeed in maintaining and enhancing the skills of the working population, or in easing the transition between jobs. In this paper we combine the Danish matched worker-firm-trade data with detailed information on workers' participation in vocational and post-secondary training programs that are heavily subsidized by the Danish government. Our goal is to develop a set of stylized facts related to offshoring, 
training, and labor-market transition in Denmark. We track training take-ups before, during, and after displacement, and examine how they vary with worker and firm characteristics. We focus on workers employed in firms that had mass-layoff events, classifying them into four groups based on whether or not they are laid off (displaced versus staying workers) and whether or not their employers substantially increased offshoring immediately before mass lay-off (offshorers versus non-offshorers). We next examine the transition of displaced workers in the short- and medium-run. We find significant differences in training take-ups and transition between these four groups relative to the general population (i.e. the other workers in our sample) and relative to each other. We then draw out suggestive inferences about the relationship between training, offshoring, and transition to new employment. For example, we find that displaced offshorers have higher vocational-training take-up rates than displaced non-offshorers, and they also have a harder time getting re-attached to the labor force. This suggests that adjustment costs are likely higher for displaced offshorers than for displaced non-offshorers.

Our paper speaks to the literature on the labor-market response to trade liberalization. ${ }^{1}$ Our contribution is to compare the adjustment of workers displaced from offshoring firms relative to those displaced for other reasons, and to provide stylized facts about the training takeup of displaced workers. Our paper also relates to the literature evaluating the benefits of training programs. Heckman, LaLonde and Smith (1999) argue that training take-up reveals whether workers regard training programs as beneficial. In that vein we study whether workers displaced due to offshoring regard these programs as more beneficial than other displaced workers.

\section{Training Programs in Denmark}

\footnotetext{
1 e.g. Davidson and Matusz 2009, Krishna and Senses 2009, Helpman, Itskhoki and Redding 2010, Cosar 2011, Menezes-Filho and Muendler 2011.
} 
In this section we briefly describe the training programs in Denmark. For more institutional details see Simonsen and Skipper (2008). The Danish labor market features the socalled "flexicurity system" in which low regulation and low firing costs similar to the US are combined with the continental European system of high social protection (OECD 2004). The Danish government heavily subsidizes worker training programs, spending around $0.5 \%$ of GDP each year (equal to its expenses on ordinary post-secondary education). Unique among OECD countries, the government provides and finances worker training at off-the-job training sites, and offers generous wage subsidies for firms offering training during work hours. This results in an unusually high incidence of training participation among employed workers.

The training courses can be grouped into basic, vocational, and post-secondary training. ${ }^{2}$ Vocational courses represent most of training activities in Denmark and 77\% of government training expenditures. They last 2-3 weeks and cover firm-specific (e.g. "team work at the plant”, "management and cooperation at the assembly line”), industry- or occupation-specific materials (e.g. production, construction). Vocational training typically requires employer sponsorship and takes place during work hours. ${ }^{3}$ The government covers most of the expenses and provides firms with subsidies of $60-80 \%$ of wages during training, while the workers themselves pay only token tuition (€25 per course per week). Post-secondary training typically take place during off-work hours and consist of poly-technical, college or MBA type courses. They do not require employer sponsorship and have very low tuition. Because the government co-sponsors much of the training in Denmark, precise information on training histories at the individual level is collected and recorded at central registers. By joining this to data on workers, firms, and trade employed by

\footnotetext{
${ }^{2}$ Basic courses focus on literacy and basic skills (at the third to tenth grade level) and target adults with only little or obsolete education. They typically take place during off-work hours and are open to anybody who wishes to participate, essentially tuition free.

${ }^{3}$ The unemployed can only participate if there are more spaces than all the employer-sponsored participants.
} 
HJMX 2011 we can examine training behavior throughout the Danish economy.

\section{Specification, Data, and Training Take-up}

In this section we examine training take-ups for the firms that lay off large numbers of workers. Jacobson, LaLonde and Sullivan (1993) (JLS 1993 henceforth) study the evolution of earnings for displaced workers relative to non-displaced workers in the years around displacement. Like JLS we use mass lay-offs to identify genuine displacement as opposed to voluntary quits. We use an estimating framework similar to JLS 1993, except that the dependent variable is participation in training programs ${ }^{4}$. We estimate

$$
P_{i s}=\alpha_{i}+\alpha_{s}+x_{i s} \beta+\sum_{k \geq-m} D_{i s}^{k} c_{i} \delta_{k}+\varepsilon_{i s}, c_{i}=\left(S O_{i}, S N_{i}, D O_{i}, D N_{i}\right) \text {, }
$$

where $i$ and $s$ index workers and years. The dependent variable, $P_{i s}$, is a dummy that equals 1 if worker $i$ completes a training program in year s. $\alpha_{i}$ and $\alpha_{s}$ are worker and year fixed effects, and $x_{i s}$ is a vector of time-varying worker characteristics as controls. ${ }^{5}$ Equation (1) estimates training profiles for the three years before and three years after the mass layoff event in year $\mathrm{t}$, with seven dummy variables, $D_{i t}^{k}$, corresponding to those years. ${ }^{6}$ The vector $c_{i}$ distinguishes four groups of workers employed by the mass-lay-off firms, displaced (D) and staying (S) workers employed in firms who are offshorers $(\mathrm{O})$ and non-offshorers $(\mathrm{N})$. The residual category is then all the workers who are not employed by the mass-lay-off firms, whose average training take-up rates form the baseline values (conditional on $\alpha_{i}, \alpha_{s}$ and $x_{i s}$ ). For each of the four groups of workers, the seven coefficients in the vector $\delta_{k}$ show the differences in their training take-up rates relative to the baseline values in each of the 7 years (again conditional on $\alpha_{i}, \alpha_{s}$ and $x_{i s}$ ).

\footnotetext{
${ }^{4}$ Unlike JLS 1993, equation (1) uses year dummies rather than linear trends to capture changes in the dependent variable around a mass lay-off.

${ }^{5}$ They include union, marriage, education status, firm size and a routine-ness measure of the worker's occupation.

${ }^{6}$ The year $\mathrm{t}$ varies across firms and workers; i.e. $\mathrm{t}$ may be 1999 for one firm and its employees but 2000 for another firm and its employees.
} 
Our sample consists of 116,190 workers and 1.39 million worker-year observations. Following JLS 1993 we require that all workers be observed throughout 1995-2006. ${ }^{7}$ Mass layoffs are when firms reduce employment by at least $30 \%$ from one year (i.e. year t-1) to another (i.e. year t). Following HJMX 2011 all our workers are manufacturing workers who, in at least one of the years 1997-2000, are full-time employed by a firm that imports at least DKK 600,000 and has at least 50 employees. We classify worker $i$ as an "offshorer" if his/her employer increased predicted offshoring by at least $10 \%$ immediately before mass layoff (i.e. from year t-1 to t). ${ }^{8}$ We use predicted offshoring taken from HJMX 2011 to capture changes in offshoring due to exogenous events (supply shocks in foreign markets) rather than technological change endogenous to the firm.

We summarize the estimation results in Figure 1, which plots the difference in vocational training take-up rate around the mass layoff event year $t$ (" $\mathrm{x}$ " indicates that coefficients are significant at the $5 \%$ level). The top graph shows staying workers (i.e. those who remain employed with the mass-lay-off firms) relative to the baseline values, and the bottom graph shows displaced workers relative to baseline values.

These graphs reveal three main findings. One, displaced workers increase their training take-up rates in the year of displacement. While training spikes for workers displaced from both types of firms, the effect is nearly three times larger for workers displaced from offshoring firms. The average take-up rate in this sample is $19.4 \%$, so the $7 \%$ increase in training for displaced offshorers represents a training rate 36 percent higher than the rest of the population. It is not

\footnotetext{
${ }^{7}$ A worker is not observed in our sample if he/she dies or migrates out of Denmark.

${ }^{8}$ Approximately 9\% of the workers are displaced in a mass layoff event at least once over the years 1998-2006 and $33 \%$ remain employed with the mass-lay-off firms. One third of the displaced or affected workers do not have an observed change in predicted offshoring in the pre-displacement firm, due to missing instruments for some firms and to the fact that some of the pre-displacement firms closed down. Of the remaining two thirds, roughly $25 \%$ are classified as offshorers.
} 
surprising that displacement may require workers to retrain to find employment in a new firm. What is novel in our results is that workers displaced from offshoring firms require this retraining at substantially higher rates than other displaced workers. This is broadly consistent with the idea that offshoring is transforming job availability not only within the firm but throughout the economy, making it more difficult for the worker to find employment with their existing skill set.

The second finding is that for stayers within offshoring firms training also rises sharply, an increase of over $6 \%$ in years $t$ and $t+1$. There is no corresponding increase for stayers within non-offshoring firms. One explanation for this difference is that offshoring may involve reorganization of production within the firm. As offshoring changes the set of tasks performed within the firm, the firm may adjust its workforce both through lay-offs and by reshuffling the task assignments of the workers who stay. This reshuffling shows up as higher take-up rates in vocational training as long as such training helps workers learn their new tasks.

The third finding is that for workers displaced from offshoring firms, training take-up increases sharply (5\%) in year $\mathrm{t}-2$. This pre-displacement spike occurs for no other group. What's going on?

One hypothesis is expectations. If both offshoring and mass lay-off can be predicted 2 years in advance, then workers might take up vocational training to prepare for future job search. We believe this is very unlikely due to the nature of the training programs. In order to participate in vocational training, a worker must be sponsored by their employer, and while training is subsidized by the government the firm still bears wage costs and lost production while workers are training. Presumably then, the firm must perceive a benefit to training the worker. It makes no sense to think that a firm would incur costs to train a worker in anticipation of a mass 
layoff when the benefits of that training will be enjoyed by another firm post-displacement. This point is reinforced by noting two additional patterns. Offshoring firms increase training for stayers in year $t$ and $t+1$ (suggesting that training is beneficial for these workers), but they do not seem to anticipate this need with higher training pre-displacement. Further, workers displaced from non-offshoring firms do not experience higher training in t-2, which suggests that they (or their firms) are not anticipating displacement.

A more likely hypothesis is that there is some relationship between the worker, the need for training, and the likelihood that the task in question can be offshored. Vocational training takes place in courses lasting 2-3 weeks. If a task requires training a Danish worker for only this short time, perhaps that same task can easily be taught to a foreign worker and offshored. This suggests two scenarios. One, certain types of workers self-select into offshorable occupations whose nature also requires frequent vocational training. Two, the training programs themselves induce workers to select into occupations that are more at risk for offshoring. We leave to future work understanding which scenario best explains the data.

What about take-up of post-secondary training? This seems an especially attractive option for displaced workers since it is low cost, does not require employer sponsorship, and may open the door to occupations in non-tradable service or public sector employment that are more insulated from globalization shocks. Moreover, HJMX (2011) show that offshoring shocks raising returns to post-secondary education within manufacturing both absolutely and relative to secondary education. Despite these attractions, displaced workers, both offshorers and nonoffshorers, are no more likely to take up post-secondary training than the general population.

\section{Transition of Displaced Workers}


A useful feature of our data is that we can track the workers over time regardless of their employment status or employer identities. In this section we examine whether there are any obvious differences in the types of employment workers transition into as a function of displacement type (offshorer, non-offshorer) and their history of training prior to displacement (whether or not they are trained, or completed vocational training in year $t-1$ ). We examine transitions in the short run (1 year after mass displacement) and in the medium run ( 3 years after). The top panel of Table 1 shows the short-run labor market status for displaced workers, which we classify into four categories: without employment (either unemployed or out of the workforce), and employment with public plus primary (i.e. agricultural), service, or manufacturing sectors. ${ }^{9}$. Workers displaced from offshoring firms are much more likely to be without employment in $t+1$ than workers displaced from non-offshoring firms (24.6\% versus 16.7\%). These results are consistent with the view that offshoring shocks affect the availability of certain tasks economy-wide, reducing the likelihood that offshorers can find employment using the same skills in a new firm. The employment differential is especially large for trained workers. For workers with employment, all groups sort into public, primary and service sectors at similar rates. There is a sizable difference in manufacturing re-employment, but this mainly reflects the fact that displaced non-offshorers have an easier time transitioning back into manufacturing than displaced offshorers.

The bottom panel of Table 1 shows the medium-run labor market status. Now the fraction of displaced offshorers without employment (9.5\%) is similar to non-offshorers (9.9\%), and offshorers are more likely to employ with manufacturing (70.4\%) than non-offshorers (66.3\%). In addition, trained workers are less likely to be without employment than non-trained workers

\footnotetext{
${ }^{9}$ To keep track of all the displaced workers in our sample we examine all the employers in the Danish economy. Our data covers the universe of private-sector Danish employers but its coverage for the public sector is less complete. As a result we lack employer information for 3 percent of the displaced workers.
} 
(e.g. $3.9 \%$ vs. $10.8 \%$ for offshorers), less likely to employ with service (e.g. $9.8 \%$ vs. $15.1 \%$ for offshorers), and more likely to employ with manufacturing (e.g. $73.3 \%$ vs. $65 \%$ for nonoffshorers). These results again suggest interactions between worker characteristics, training, and job requirements. When the trained manufacturing workers are displaced they do not take up heavily subsidized post-secondary education that would allow them to transition to public or service sector jobs. Instead, they undergo more vocational training and three years after displacement they are back in manufacturing at higher rates than other displaced workers. This may reflect worker self-seclection. Another hypothesis is that readily-available and heavilysubsidized training programs re-enforce these workers' attachment to specific types of manufacturing jobs, making it more likely that they seek employment in manufacturing.

\section{Conclusion and Discussion}

We report several stylized facts about the take-up rates of vocational and post-secondary training before, during, and after mass lay-offs, and about the transition of mass-laid-off workers in the short- and medium-run. Two broad themes emerge from our findings. First, there are large differences between the workers whose employers substantially increased offshoring prior to mass lay-off (offshorers) and those employed by other mass lay-off firms (non-offshorers). Workers displaced from offshoring firms train at much higher rates after displacement than other displaced workers and suffer greater unemployment in the short term. Even those workers who remain employed in offshoring firms after a mass-layoff event exhibit a sharp rise in training activity. Many of our findings suggest interactions between worker characteristics, job requirements, and training. Workers who will be displaced from offshoring firms train at higher rates two years before displacement. Workers displaced from mass layoffs are no more likely to 
take up post-secondary training than the general population; instead, many of them take up vocational training and tend to re-employ with manufacturing.

These results suggest several future avenues of research. What exactly are the characteristics (routineness? hazardous working conditions?) of tasks that are both offshorable and require greater vocational training? Does training actually increase the risk that workers will be subject to offshoring shocks further down the road? Do the results on training take-up for workers who stay in offshoring firms indicate that offshoring create new tasks within a firm, and if so, what are those tasks? Given the difference between offshorers and non-offshorers, does it make sense for Denmark, and other OECD countries, to adopt training programs that favor the workers displaced by globalization, such as the Trade-Adjustment-Assistance programs in the

U.S.? Ultimately, do the benefits of training programs in Denmark justify an expense equal to 0.5 percent of GDP?

\section{References}

Cosar, Kerem A., 2011, “Adjusting to Trade Liberalization: Reallocation and Labor Market Policies", mimeo, University of Chicago.

Davidson, Carl, and Steven J. Matusz, 2009, International Trade with Equilibrium Unemployment, Princeton University Press.

Heckman, James J., Robert J. LaLonde and Jeffrey A. Smith, 1999, "The Economics and Econometrics of Active Labor Market Programs”, in Handbook of Labor Economics, Eds. Orley C. Ashenfelter and David Card, Vol. 3A, North-Holland.

Helpman, Elhanan, Oleg Itskhoki and Stephen Redding. 2010. "Inequality and Unemployment in a Global Economy”. Econometrica 78(4), 1239-1283.

Hummels, David, Rasmus Jørgensen, Jakob R. Munch, and Chong Xiang, 2011, “The Wage Effects of Offshoring: Evidence from Danish Matched Worker-Firm Data”, NBER working paper 17496.

Jacobson, L. S., R. J. LaLonde, and D. G. Sullivan, 1993, “Earnings losses of displaced workers”, American Economic Review 83, pp. 685-709.

Krishna, Pravin and Mine Zeynep Senses, 2009, "International Trade and Labor Market Income Risk in the United States", NBER working paper 14992.

Menezes-Filho, Naercio A. and Marc-Andreas Muendler, 2011. "Labor Reallocation in Response to Trade Reform”, NBER Working Paper 17372.

Simonsen, Marianne and Lars Skipper, 2008, "The Incidence and Intensity of Formal Lifelong Learning”, mimeo. 
Figure 1 Vocational-training Take-up Rates
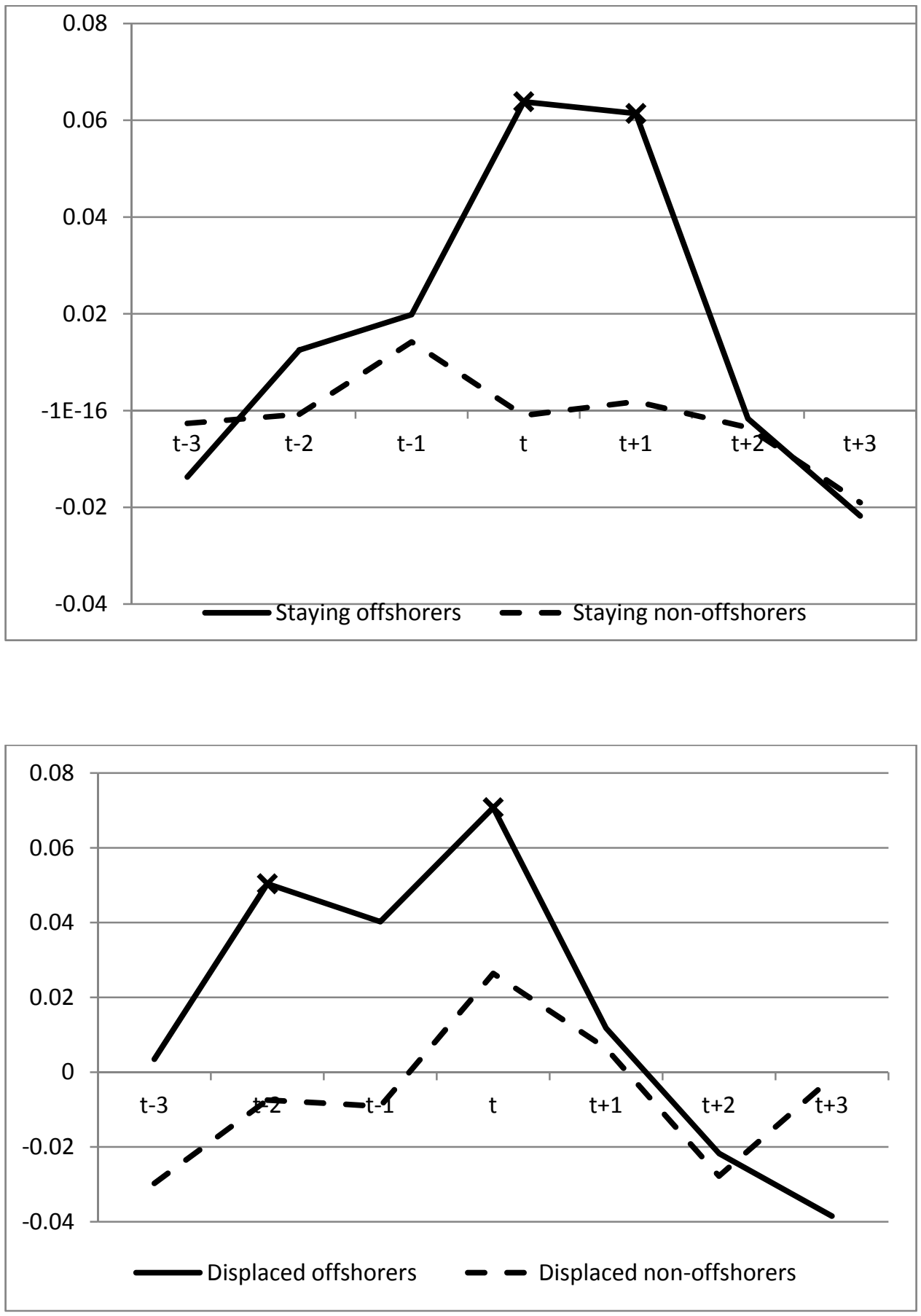
Table 1 Transition for Displaced Workers

\begin{tabular}{|c|c|c|c|c|c|c|}
\hline & \multicolumn{6}{|c|}{1 year after mass lay-off (\%) } \\
\hline & \multicolumn{3}{|c|}{ off-shorers } & \multicolumn{3}{|c|}{ Non-offshorers } \\
\hline & all & trained & $\begin{array}{l}\text { non- } \\
\text { trained }\end{array}$ & all & trained & $\begin{array}{c}\text { non- } \\
\text { trained }\end{array}$ \\
\hline Without employment & 24.6 & 27.5 & 23.8 & 16.7 & 14.3 & 17.2 \\
\hline \multicolumn{7}{|l|}{ Employed in... } \\
\hline service & 17.7 & 15.1 & 18.4 & 17.1 & 16.5 & 17.2 \\
\hline Manufacturing & 51.8 & 48.1 & 52.8 & 61.1 & 63.1 & 60.6 \\
\hline \multirow[t]{4}{*}{ sample size } & 1,241 & 258 & 983 & 8,675 & 1,603 & 7,072 \\
\hline & \multicolumn{6}{|c|}{3 years after mass lay-off (\%) } \\
\hline & \multicolumn{3}{|c|}{ off-shorers } & \multicolumn{3}{|c|}{ Non-offshorers } \\
\hline & all & trained & $\begin{array}{l}\text { non- } \\
\text { trained }\end{array}$ & all & trained & $\begin{array}{l}\text { non- } \\
\text { trained }\end{array}$ \\
\hline Without employment & 9.5 & 3.9 & 10.8 & 9.9 & 7.7 & 10.3 \\
\hline \multicolumn{7}{|l|}{ Employed in... } \\
\hline service & 14.1 & 9.8 & 15.1 & 18.0 & 13.7 & 18.8 \\
\hline Manufacturing & 70.4 & 77.8 & 68.7 & 66.3 & 73.3 & 65.0 \\
\hline sample size & 850 & 153 & 697 & 6,734 & 1,075 & 5,659 \\
\hline
\end{tabular}

